\title{
Obstructive sleep apnea syndrome and risk of renal impairment: a systematic review and meta-analysis with trial sequential analysis
}

\author{
Tongtong Liu ${ }^{1} \cdot$ Yongli Zhan ${ }^{1} \cdot$ Yuyang Wang ${ }^{1} \cdot$ Qian $\mathrm{Li}^{1} \cdot$ Huimin Mao ${ }^{1}$
}

Received: 11 February 2020 / Revised: 11 February 2020 / Accepted: 17 April 2020 / Published online: 21 May 2020

(C) The Author(s) 2020

\begin{abstract}
Background Obstructive sleep apnea syndrome (OSAS) is associated with a variety of systemic diseases. Among patients with chronic kidney diseases (CKD), the prevalence of OSAS is high. OSAS can induce progression of CKD. However, whether or not OSAS can cause renal damage in healthy people is not clear. Thus, the purpose of this meta-analysis was to elucidate whether or not there was an association between OSAS and early renal damage.

Methods PubMed, Embase Database, Cochrane Library, Web of Science, China National Knowledge Infrastructure, China Biology Medicine Database, Chinese Scientific Journals Database, and Wanfang Database were searched systematically. The relative risk (RR), weighted mean difference (WMD), and 95\% confidence intervals (CI) were used to evaluate the relationship between OSAS and early renal damage. Funnel plot and Egger's test were used to evaluate publication bias, and trial sequential analysis (TSA) was employed to verify the sufficiency of the research conclusions. Results A total of 18 studies were analyzed comprising 4,567 participants. Compared with the healthy control group, levels of cystatin $\mathrm{C}(\mathrm{MD}=0.530,95 \% \mathrm{CI} 0.423,0.637, \mathrm{P}<0.01)$ and proteinuria in patients with OSAS were significantly increased, while the levels of estimated glomerular filtration rate (eGFR) $(\mathrm{MD}=-0.194,95 \% \mathrm{CI}-0.268,-0.121, \mathrm{P}<0.01$ ) were significantly decreased. Furthermore, patients with OSAS also had an increased risk of CKD. Subgroup analysis showed that compared with patients without OSAS, the level of serum cystatin $\mathrm{C}$ in patients with OSAS was significantly increased independent of hypertension and diabetes, and the eGFR was significantly decreased in patients with moderate to severe OSAS and comorbid hypertension and/or diabetes.

Conclusion In this meta-analysis, OSAS was associated with a higher risk of early renal damage. Patients with OSAS and comorbid hypertension and/or diabetes appear to suffer from severe renal damage.
\end{abstract}

Keywords Obstructive sleep apnea syndrome $\cdot$ Renal damage $\cdot$ Cystatin $C \cdot$ Meta-analysis $\cdot$ Trial sequential analysis

\section{Introduction}

Obstructive sleep apnea syndrome (OSAS) is one of the common forms of sleep disorders, characterized by recurrent episodes of apnea and hypopnea due to obstruction of the upper airway during sleep [1]. Evidence obtained from clinical study supports that the risk of several comorbidities, including cardiovascular events [2, 3], stroke [4], diabetes [5], and chronic

Huimin Mao

maomolly@sina.com

1 Guang'anmen Hospital, China Academy of Chinese Medical Sciences, No.5, Bei Xian Ge Street, Xicheng District, Beijing 100053, China kidney disease [6], among patients with OSAS is high. It is reported that more than 57\% patients with CKD are suffering from OSAS [7], accompanied with unfavorable prognosis and an increase in mortality $[8,9]$.

Serum cystatin $\mathrm{C}$ and urinary microalbuminuria are much earlier and sensitive biomarkers for renal impairment [10]. Emerging studies have found that OSAS was significantly associated with increased cystatin $\mathrm{C}$ and microalbuminuria excretion in patients without CKD [11, 12]. Studies related to the relationship between OSAS and potential renal impairment suggest opposite results [13]. Therefore, a meta-analysis is needed for further assessment. The purpose of the current study was to evaluate the possible risk of renal impairment in OSAS patients, which might help to offer novel strategies for treatment and risk assessment. 


\section{Materials and methods}

This meta-analysis was conducted based on Preferred Reporting Items for Systematic Review and Meta-Analyses (PRISMA) checklist [14].

\section{Literature retrieval strategy}

PubMed, EMBASE Database, Cochrane Library, Web of Science, China National Knowledge Infrastructure (CNKI), China Biology Medicine Database (CBM), Chinese Scientific Journals Database (VIP), and Wanfang Database were independently searched by two researchers (from database inception to December 2019). The MeSH and keywords adjusted according to the characteristics of different databases were as follows: obstructive sleep apnea syndrome, sleep apnea, apnea-hypopnea index (AHI), sleep-associated breathing disorder, OSAS, OSA, SA, renal damage, renal dysfunction, serum cystain $C$, and microalbuminuria. This study includes English and Chinese. The flowchart for the process of literature selection is shown in Fig. 1.

\section{Inclusion and exclusion criteria}

Clinical studies eligible for this meta-analysis included cohort studies and case-control studies. Studies were considered eligible if they (1) enrolled participants with OSAS, (2) enrolled participants without CKD, (3) compared the risk of renal damage with healthy control group, and (4) provided information on any of the primary or secondary outcomes.

\section{Data extraction and quality assessment}

Two researchers (HM MAO and Q LI) screened the literature independently according to the inclusion and exclusion criteria, and rescreened and extracted data for the remaining retrieval results. The literature in dispute or unable to extract data needs to be discussed with the third researcher (YL ZHAN). The content of the extracted data includes the following: the basic information, the sample size of participants, the assessment tools of OSAS, and the outcome index. The Newcastle-Ottawa Scale (NOS) provided by Cochrance was used to evaluate the quality of the included studies.
Fig. 1 Flow chart for the process of literature selection
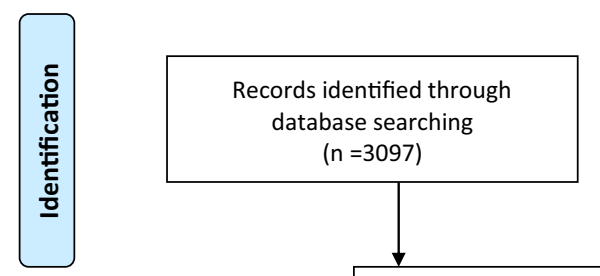

Additional records identified through other sources $(\mathrm{n}=3097)$

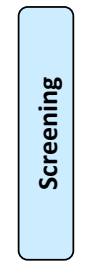

Records after duplicates removed ( $n=1215$ )
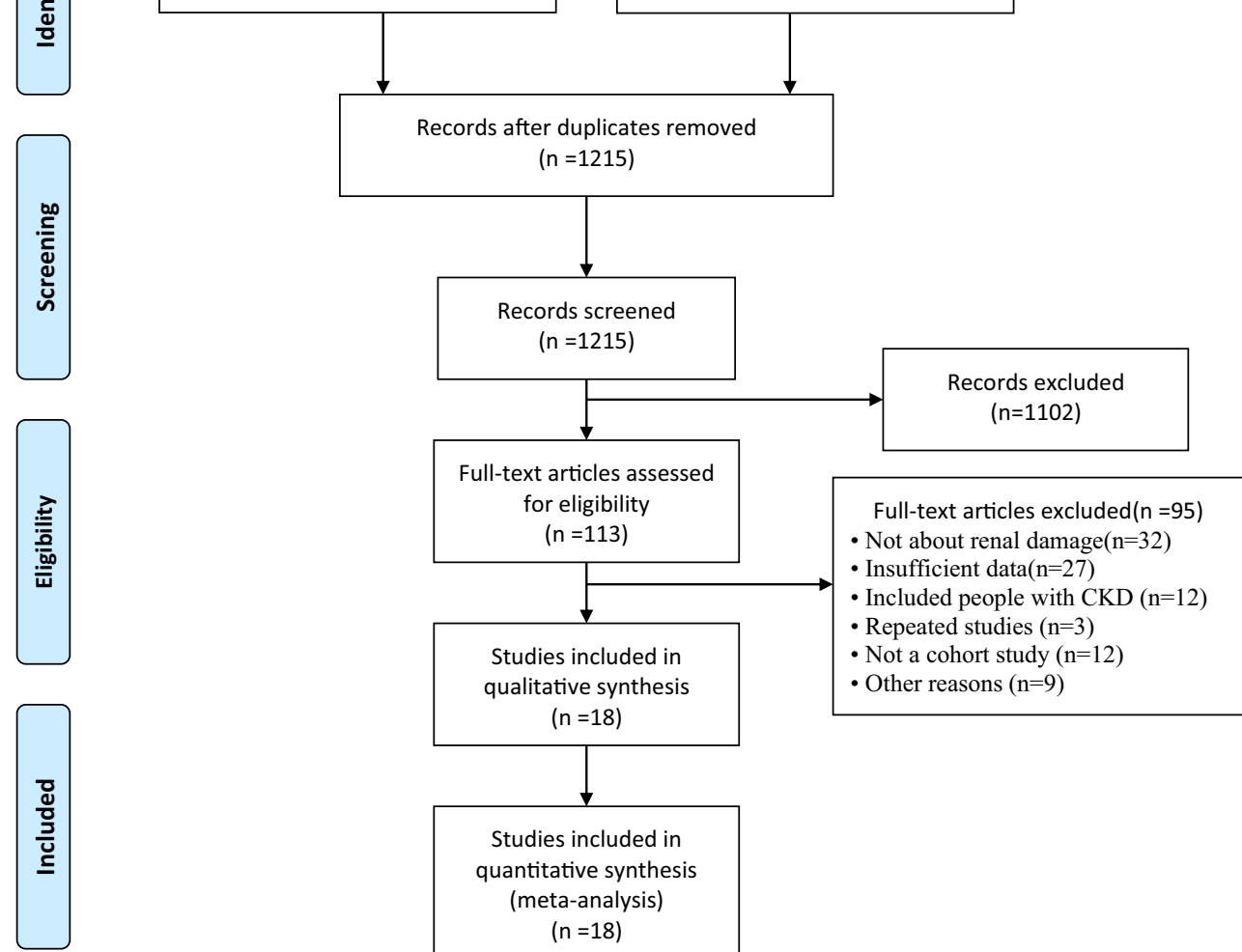

Full-text articles assessed for eligibility $(n=113)$

Records excluded $(n=1102)$

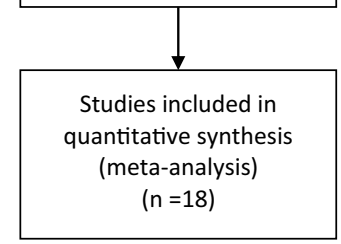

Full-text articles excluded( $n=95$ )

- Not about renal damage $(n=32)$

sufficient data $(n=27)$

- Repeated studies $(\mathrm{n}=3)$

- Other reasons $(\mathrm{n}=9)$ 


\section{Outcomes}

The primary outcome of this meta-analysis was serum cystatin C. The secondary outcomes were (1) eGFR (as assessment by study authors), (2) incidence of CKD (defined as eGFR < $60 \mathrm{ml} / \mathrm{min} / 1.73 \mathrm{~m}^{2}$ ), and (3) progression of albuminuriarelated indexes (including albumin/creatinine ratio, incidence of microalbuminuria, and the levels of microalbuminuria).

\section{Statistical analyses}

The meta-analysis was carried out with STATA 14.0, and the trial sequential analysis (TSA) was carried out with TSA0.9. If the study data was enumeration data, the relative risk (RR) and 95\% confidence intervals (CI) were used as the statistical effect quantity; otherwise, the standardized mean difference (SMD) and $95 \%$ CI were used as the statistical effect quantity to evaluate the relationship between OSAS and renal damage. Chi-squared test and $\mathrm{I}^{2}$ statistic were used to test the heterogeneity of the included studies. When $P>0.05$ and $\mathrm{I}^{2}<50 \%$, fixed effect model was used for meta-analysis; otherwise, random effect model was used. At the same time, funnel chart and Egger's test were used to evaluate the potential publication bias. Finally, TSA of the main results were analyzed in order to evaluate the adjusted statistical significance threshold and the required information size (RIS), so as to correct and reduce the random error.

\section{Results}

A total of 3097 related literatures were retrieved. After removing the repetition, reading title and abstract, and further reading the full text, 18 cross-sectional studies [11, 12, 15-30] were included and the NOS score of each study were all above 5. A total of 4567 participants were included: 3472 with OSAS and 1095 in healthy control group. Among the included OSAS patients, 574 were with mild OSAS, 618 with moderate OSAS, 698 with severe OSAS, and other 1582 with unidentified stage of OSAS (the severity of OSAS was assessed by study authors). These studies are conducted in different countries, such as USA [11, 17, 19], China [15, 16, $18,23,24,28,30]$, Greece [12, 20], Turkey [21, 22, 26], Germany [25], and Australia [27]. Six studies [12, 16, 18, $20,21,28]$ controlled the confounding factors such as diabetes and high blood pressure. The characteristics of the included studies are shown in Table 1.

Table 1 The characteristics of the included studies

\begin{tabular}{|c|c|c|c|c|c|c|c|c|c|c|}
\hline \multirow[t]{2}{*}{ Study } & \multirow[t]{2}{*}{ Country } & \multirow[t]{2}{*}{$\begin{array}{l}\text { No. of } \\
\text { participants }\end{array}$} & \multicolumn{2}{|c|}{$\begin{array}{l}\text { No. of } \\
\text { comorbidity }\end{array}$} & \multirow{2}{*}{$\begin{array}{l}\text { No. of } \\
\text { subjects } \\
\text { (case/control) }\end{array}$} & \multirow[t]{2}{*}{$\begin{array}{l}\text { Sex } \\
\text { male }(\%)\end{array}$} & \multirow[t]{2}{*}{ Age (year) } & \multirow[t]{2}{*}{$\begin{array}{l}\text { Assessment } \\
\text { of OSAS }\end{array}$} & \multirow[t]{2}{*}{ Outcome } & \multirow[t]{2}{*}{$\begin{array}{l}\text { Quality } \\
\text { score }\end{array}$} \\
\hline & & & DM & HTN & & & & & & \\
\hline Agrawal2009 [11] & USA & 91 & 31 & 55 & $36 / 55$ & $27.1 \%$ & $44.9 \pm 9.9$ & PSG, $\mathrm{AHI} \geq 5$ & (3) (4) & 8 \\
\hline Voulgaris2018 [12] & Greece & 96 & 0 & 0 & $32 / 64$ & $79.17 \%$ & $50.7 \pm 11.98$ & $\mathrm{PSG}, \mathrm{AHI} \geq 5$ & (1)(2) & 7 \\
\hline Chen2015 [15] & China & 457 & 0 & 457 & $106 / 351$ & $64.11 \%$ & $20 \sim 78$ & $\mathrm{PSG}, \mathrm{AHI} \geq 10$ & (1)(4) & 7 \\
\hline Chen2019 [16] & China & 90 & 0 & 0 & $17 / 73$ & NA & $42.50 \pm 11.46$ & $\mathrm{PSG}, \mathrm{AHI} \geq 10$ & (1)(2) & 7 \\
\hline Canales2011 [17] & USA & 507 & 66 & 359 & $120 / 387$ & $100 \%$ & $76.0 \pm 5.3$ & $\mathrm{PSG}, \mathrm{RDI} \geq 5$ & (2) (3) (4) & 8 \\
\hline Zhang2013 [18] & China & 98 & 0 & 0 & $23 / 75$ & $100 \%$ & $32.5 \pm 5.19$ & $\mathrm{PSG}, \mathrm{AHI} \geq 5$ & (1)(2) & 6 \\
\hline Faulx2007 [19] & USA & 496 & 172 & 63 & $233 / 263$ & $44.4 \%$ & $44.5 \pm 17.3$ & $\mathrm{PSG}, \mathrm{AHI} \geq 5$ & (2)(3) & 7 \\
\hline Archontogeorgis 2016 [20] & Greece & 84 & 0 & 0 & $20 / 64$ & $80.95 \%$ & $51.69 \pm 12.71$ & $\mathrm{PSG}, \mathrm{AHI} \geq 5$ & (1)(2) & 7 \\
\hline Ursavas2008 [21] & Turkey & 46 & 0 & 0 & $11 / 35$ & $100 \%$ & $45.12 \pm 10.67$ & $\mathrm{PSG}, \mathrm{AHI} \geq 5$ & (3) & 6 \\
\hline Bulcun2015 [22] & Turkey & 124 & 0 & NA & $26 / 98$ & $74.19 \%$ & $48.38 \pm 11.79$ & PSG, AHI $\geq 5$ & (2)(3) (4) & 6 \\
\hline Song2019 [23] & China & 487 & 49 & 331 & $54 / 433$ & $84.8 \%$ & $40.08 \pm 11.6$ & $\mathrm{PSG}, \mathrm{AHI} \geq 5$ & (1)(2) & 6 \\
\hline Zeng2017 [24] & China & 109 & 8 & 21 & $26 / 83$ & $100 \%$ & 45.72 & $\mathrm{PSG}, \mathrm{AHI} \geq 5$ & (2)(3) & 6 \\
\hline Yayan2017 [25] & Germany & 382 & NA & NA & $19 / 363$ & $69.63 \%$ & $63.75 \pm 13.85$ & $\mathrm{PSG}, \mathrm{AHI} \geq 5$ & (4) & 5 \\
\hline Uyar2015 [26] & Turkey & 696 & 0 & 275 & $62 / 634$ & $68.1 \%$ & $51.09 \pm 11.82$ & $\mathrm{PSG}, \mathrm{AHI} \geq 5$ & (3) & 6 \\
\hline Robert2017 [27] & Australia & 489 & NA & NA & $237 / 252$ & NA & NA & $\mathrm{PSG}, \mathrm{AHI} \geq 10$ & (4) & 8 \\
\hline Chou2011 [28] & $\begin{array}{l}\text { Taiwan, } \\
\text { China }\end{array}$ & 40 & 0 & 0 & $3 / 37$ & $83 \%$ & $44.8 \pm 8.6$ & PSG, $\mathrm{AHI} \geq 5$ & (5) & 7 \\
\hline Kanbay2012 [29] & Turkey & 175 & 30 & 34 & $25 / 150$ & $66.86 \%$ & $53.94 \pm 12.16$ & PSG, $\mathrm{AHI} \geq 5$ & (3) & 7 \\
\hline Hou2016 [30] & China & 100 & 0 & 100 & $45 / 55$ & $60 \%$ & $55.04 \pm 11.09$ & $\mathrm{PSG}, \mathrm{AHI} \geq 5$ & (1) & 7 \\
\hline
\end{tabular}

PSG, polysomnography; $D M$, diabetes mellitus; $H T N$, hypertension; $A H I$, apnea-hypopnea index; outcome, (1) cystatin C; (2) eGFR; (3) ACR; (4) albuminuria; (5) new-onset CKD 


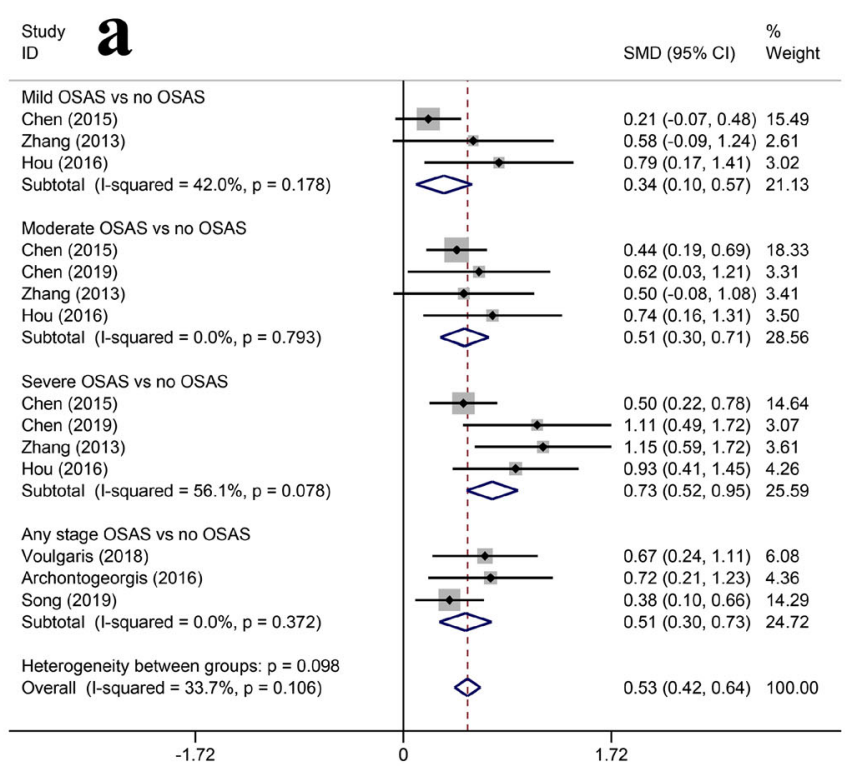

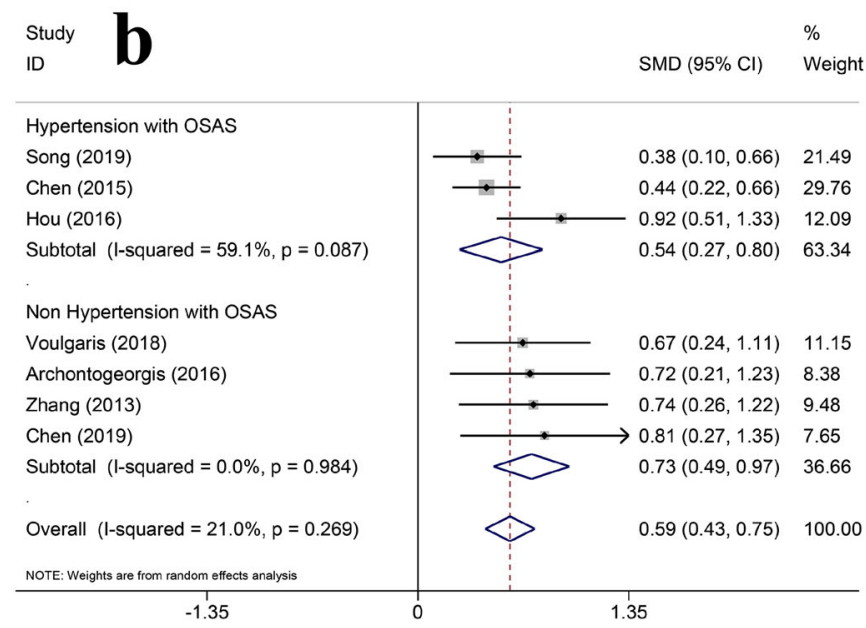

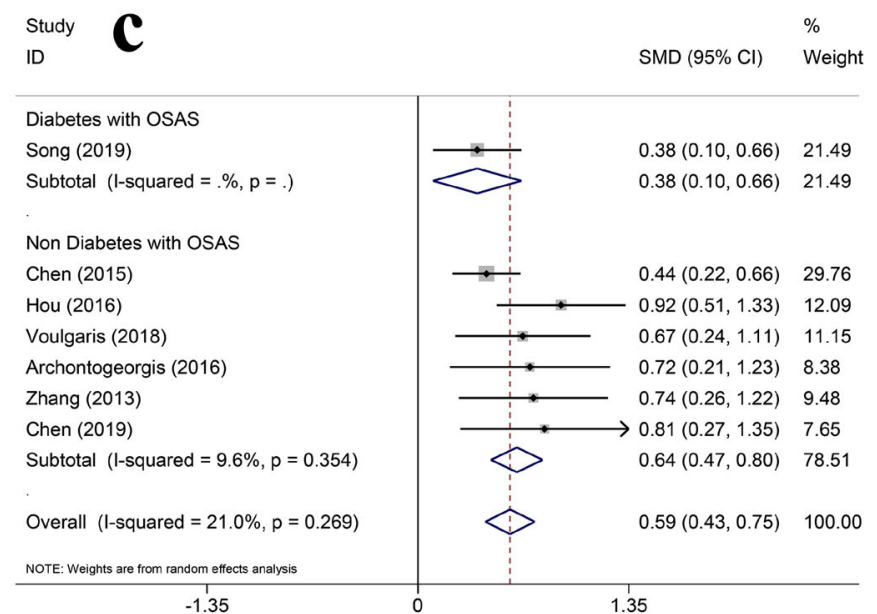

Fig. 2 Forest plots of the association between serum OSAS and cystatin C. a Relationship between severity of OSAS and cystatin C. b
Relationship between hypertension and cystatin C in OSAS patients. $\mathbf{c}$ Relationship between diabetes and cystatin C in OSAS patients 
Table 2 Meta-analysis of association between OSAS and renal damage

\begin{tabular}{|c|c|c|c|c|c|c|c|}
\hline \multirow[t]{2}{*}{ Outcome } & \multirow[t]{2}{*}{ Subgroup } & \multirow[t]{2}{*}{ No. of studies } & \multicolumn{2}{|c|}{ Heterogeneity } & \multicolumn{3}{|l|}{ Effect size } \\
\hline & & & $P$ & $\mathrm{I}^{2}$ & Pooled SMD & $95 \%$ CI & $P$ \\
\hline \multirow[t]{11}{*}{ Serum cystatin $\mathrm{C}$} & Mild OSAS vs. no OSAS & 3 & 0.178 & $42.0 \%$ & 0.335 & $0.102,0.569$ & $<0.01$ \\
\hline & Moderate OSAS vs. no OSAS & 4 & 0.793 & $0.0 \%$ & 0.506 & $0.305,0.706$ & $<0.01$ \\
\hline & Severe OSAS vs. no OSAS & 4 & 0.078 & $56.1 \%$ & 0.734 & $0.522,0.946$ & $<0.01$ \\
\hline & Any stage OSAS vs. no OSAS & 3 & 0.372 & $0.0 \%$ & 0.513 & $0.297,0.728$ & $<0.01$ \\
\hline & Overall & 7 & 0.106 & $33.7 \%$ & 0.530 & $0.423,0.637$ & $<0.01$ \\
\hline & $\begin{array}{l}\text { Hypertension with OSAS vs. } \\
\text { hypertension with no OSAS }\end{array}$ & 3 & 0.087 & $59.1 \%$ & 0.535 & $0.268,0.802$ & $<0.01$ \\
\hline & $\begin{array}{l}\text { Non-hypertension with OSAS vs. } \\
\text { non-hypertension with no OSAS }\end{array}$ & 4 & 0.984 & $0.0 \%$ & 0.730 & $0.487,0.974$ & $<0.01$ \\
\hline & Overall & 7 & 0.269 & $21.0 \%$ & 0.592 & $0.433,0.751$ & $<0.01$ \\
\hline & $\begin{array}{l}\text { Diabetes with OSAS vs. diabetes } \\
\text { with no OSAS }\end{array}$ & 1 & / & / & 0.381 & $0.097,0.665$ & $<0.01$ \\
\hline & $\begin{array}{l}\text { Non-diabetes with OSAS vs. } \\
\text { non-diabetes with no OSAS }\end{array}$ & 6 & 0.354 & $9.6 \%$ & 0.636 & $0.470,0.802$ & $<0.01$ \\
\hline & Overall & 7 & 0.269 & $21.0 \%$ & 0.592 & $0.433,0.751$ & $<0.01$ \\
\hline \multirow[t]{11}{*}{ eGFR } & Mild OSAS vs. no OSAS & 6 & 0.445 & $0.0 \%$ & -0.122 & $-0.262,0.018$ & 0.087 \\
\hline & Moderate OSAS vs. no OSAS & 7 & 0.121 & $40.6 \%$ & -0.218 & $-0.362,-0.073$ & $<0.01$ \\
\hline & severe OSAS vs. no OSAS & 7 & 0.411 & $1.8 \%$ & -0.341 & $-0.488,-0.193$ & $<0.01$ \\
\hline & Any stage OSAS vs. no OSAS & 5 & 0.077 & $52.6 \%$ & -0.096 & $-0.250,0.059$ & 0.226 \\
\hline & Overall & 13 & 0.057 & $33.1 \%$ & -0.194 & $-0.268,-0.121$ & $<0.01$ \\
\hline & $\begin{array}{l}\text { Hypertension with OSAS vs. } \\
\text { hypertension with no OSAS }\end{array}$ & 6 & 0.057 & $53.3 \%$ & -0.224 & $-0.387,-0.061$ & 0.007 \\
\hline & $\begin{array}{l}\text { Non-hypertension with OSAS vs. } \\
\text { non-hypertension with no OSAS }\end{array}$ & 4 & 0.097 & $52.5 \%$ & 0.006 & $-0.343,0.354$ & 0.975 \\
\hline & Overall & 10 & 0.016 & $55.8 \%$ & -0.159 & $-0.317,-0.002$ & 0.047 \\
\hline & $\begin{array}{l}\text { Diabetes with OSAS vs. diabetes } \\
\text { with no OSAS }\end{array}$ & 5 & 0.032 & $62.2 \%$ & -0.237 & $-0.439,-0.035$ & 0.021 \\
\hline & $\begin{array}{l}\text { Non-diabetes with OSAS vs. } \\
\text { non-diabetes with no OSAS }\end{array}$ & 6 & 0.180 & $34.2 \%$ & -0.042 & $-0.253,0.169$ & 0.699 \\
\hline & Overall & 11 & 0.021 & $52.3 \%$ & -0.149 & $-0.296,-0.001$ & 0.049 \\
\hline
\end{tabular}

\section{Serum cystatin C}

Evidence from 7 studies [12, 15, 16, 18, 20, 23, 30] (enrolling 1412 individuals) suggests that serum cystatin $\mathrm{C}$ was closely related to OSAS $(\mathrm{MD}=0.530,95 \% \mathrm{CI}(0.423,0.637)$, $P<0.01)$. The results of subgroup analysis showed that the serum cystatin $C$ increased significantly in mild, moderate and severe OSAS The level of cystatin $\mathrm{C}$ was positively correlated with the severity of OSAS, whether they have hypertension and diabetes or not (Fig. 2 and Table 2).

\section{eGFR}

We included 12 studies [12, 16-20, 22-26, 29] to explore the relationship between eGFR and OSAS, including 3344 individuals. Three studies [24-26] used the Chronic Kidney Disease Epidemiology Collaboration (CKD-EPI) formula to estimate eGFR; 6 studies $[12,16-18,20,22]$ used the Modification of Diet in Renal Disease equation (MDRD);
1 study [29] used the Cockroft-Gault equation; 1 study [19] calculated eGFR from serum cystatin $\mathrm{C}$ levels and sexcorrected; 1 study [23] used the combined creatininecystatin $\mathrm{C}$ equation. The results show that OSAS was significantly correlated with decreased eGFR $(\mathrm{MD}=-0.194$, 95\%CI $(-0.268,-0.121), P<0.01)$. The results of subgroup analysis showed that the decrease of eGFR is related to moderate and severe OSAS. The levels of eGFR decreased significantly in OSAS patients with hypertension and diabetes, but this phenomenon was not found in those who were not diagnosed with hypertension or diabetes. (Fig. 3 and Table 2).

\section{New-onset CKD}

We found that other 3 studies $[25,27,28]$ including 911 persons reported a significantly increased risk of CKD in OSAS $(\mathrm{RR}=1.847,95 \% \mathrm{CI}(1.315,2.593), P<0.01)$ (Fig. 4). 

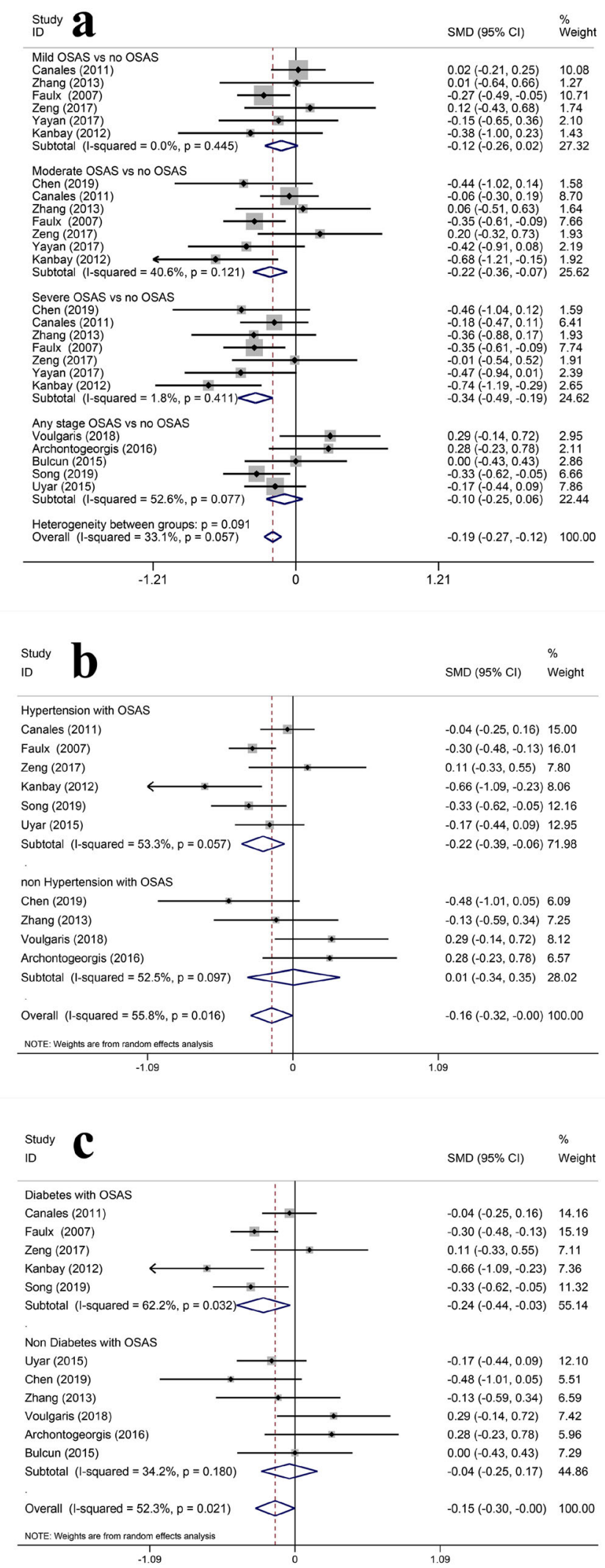

Fig. 3 Forest plots of the association between serum OSAS and eGFR. a Relationship between severity of OSAS and eGFR. b Relationship between hypertension and eGFR in OSAS patients. c Relationship between diabetes and eGFR in OSAS patients 
Fig. 4 Forest plot of the association between serum OSAS and new-onset CKD

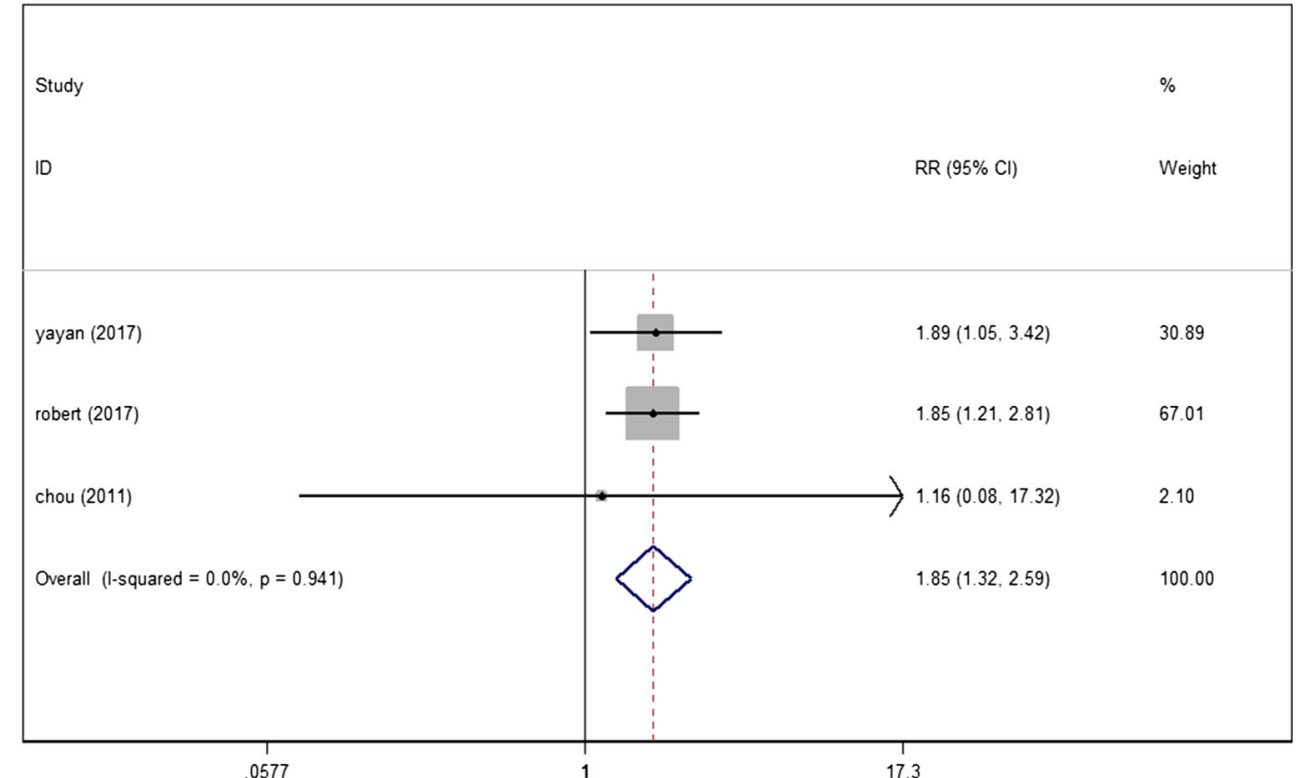

\section{Albuminuria}

Additionally, 7 studies $[11,15,17,19,21,22,24]$ found that there was a certain relationship between OSAS and albuminuria, $3[17,22,24]$ of which found that patients with OSAS had higher ACR, 4 [11, 17, 19, 22] of which found that patients with OSAS were more likely to have microalbuminuria (MAU), and $2[15,21]$ of which found that patients with OSAS had higher levels of microalbuminuria (Table 3).

\section{Publication bias}

Funnel plot and Egger's test were used to analyze the publication bias of the main indexes. Except for the subgroup of cystatin C in severe OSAS and cystatin C in OSAS without diabetes, there was no significant publication bias in other subgroup (Table 4). In order to eliminate the influence of publication bias on meta-analysis, the trim and fill analysis were carried out in subgroup of cystatin $\mathrm{C}$ in severe OSAS and cystatin $\mathrm{C}$ in OSAS without diabetes. The pooled SMD $(95 \% \mathrm{CI})$ after trim and fill analysis were 0.593 (0.782, $0.405)$ and 0.617 (0.465, 0.768) (Fig. 5).

\section{Trial sequential analysis}

We conducted a TSA of seven studies on the relationship between cystatin C and OSAS We set type I error as 5\%, and the power as $80 \%$. Based on this analysis, the accumulated Z-curve crossed the traditional and TSA thresholds and reaches the RIS (1106) (Fig. 6), which indicates that the result of meta-analysis is more robust and persuasive.

\section{Discussion}

$\mathrm{CKD}$, a public health problem, is affecting about $8 \%-16 \%$ people around the world and brings heavy economic burden

Table 3 Meta-analysis of association between OSAS and albuminuria

\begin{tabular}{|c|c|c|c|c|c|c|c|c|}
\hline \multirow[t]{2}{*}{ Outcome } & \multirow[t]{2}{*}{ No. of studies } & \multirow[t]{2}{*}{ No. of participants } & \multicolumn{2}{|c|}{ Heterogeneity } & \multirow[t]{2}{*}{ Effect model } & \multicolumn{3}{|l|}{ Effect size } \\
\hline & & & $P$ & $\mathrm{I}^{2}$ & & WMD/RR & $95 \% \mathrm{CI}$ & $P$ \\
\hline \multicolumn{9}{|l|}{ ACR } \\
\hline Mild OSAS vs. no OSAS & 2 & 352 & 0.594 & $0 \%$ & Random & 0.422 & $0.207,0.637$ & $<0.01$ \\
\hline Moderate OSAS vs. no OSAS & 2 & 306 & 0.688 & $0 \%$ & Random & 0.886 & $0.651,1.121$ & $<0.01$ \\
\hline Severe OSAS vs. no OSAS & 2 & 250 & 0.355 & $0 \%$ & Random & 1.072 & $0.801,1.342$ & $<0.01$ \\
\hline Any stage OSAS vs. no OSAS & 1 & 124 & / & / & Random & 0.375 & $-0.060,0.809$ & 0.091 \\
\hline Overall & 3 & 740 & 0.003 & $69.2 \%$ & Random & 0.712 & $0.582,0.843$ & $<0.01$ \\
\hline No. of MAU & 4 & 667 & 0.578 & $0 \%$ & Fixed & 2.316 & $1.480,3.623$ & $<0.01$ \\
\hline Levels of MAU & 2 & 502 & 0.00 & $88.5 \%$ & Random & 0.432 & $0.276,0.676$ & $<0.01$ \\
\hline
\end{tabular}


Table 4 Egger's test of outcome

\begin{tabular}{lccc}
\hline Outcome & $t$ & $P$ & $95 \%$ CI \\
\hline Serum cystatin C & & & \\
Mild OSAS vs. no OSAS & -2.97 & 0.207 & $-13.346,8.284$ \\
Moderate OSAS vs. no OSAS & -2.04 & 0.179 & $-3.294,1.178$ \\
Severe OSAS vs. no OSAS & -9.19 & 0.012 & $-5.717,-2.070$ \\
Any stage OSAS vs. no OSAS & -5.65 & 0.111 & $-10.281,3.951$ \\
HTN with OSAS vs. HTN with no OSAS & -1.49 & 0.376 & $-41.470,32.754$ \\
Non-HTN with OSAS vs. non-HTN with no OSAS & -2.54 & 0.126 & $-5.693,1.465$ \\
Diabetes with OSAS vs. diabetes with no OSAS & $/$ & $/$ & $/$ \\
Non-diabetes with OSAS vs. non-diabetes with no OSAS & -3.50 & 0.025 & $-4.321,-0.497$ \\
eGFR & & & $-22.362,14.139$ \\
Mild OSAS vs. no OSAS & -0.63 & 0.566 & $-11.788,9.120$ \\
Moderate OSAS vs. no OSAS & -0.33 & 0.756 & $-5.835,10.886$ \\
Severe OSAS vs. no OSAS & 0.78 & 0.473 & $-240.845,150.567$ \\
Any stage OSAS vs. no OSAS & -0.73 & 0.516 & $-22.584,51.134$ \\
HTN with OSAS vs. HTN with no OSAS & 1.08 & 0.343 & $-10.255,7.956$ \\
Non-HTN with OSAS vs. non-HTN with no OSAS & -0.54 & 0.641 & $-33.744,50.425$ \\
Diabetes with OSAS vs. diabetes with no OSAS & 0.63 & 0.573 & $-195.660,109.927$ \\
Non-diabetes with OSAS vs. non-diabetes with no OSAS & -0.78 & 0.480 & $-1.986,2.713$ \\
Incident CKD & 1.97 & 0.299 & $-2.913,4.900$ \\
ACR & 0.59 & 0.574 & $-6.489,4.646$ \\
No. of MAU & -0.71 & 0.550 & \\
\hline
\end{tabular}

HTN, hypertension

[31]. Diabetes, hypertension, and obesity are traditional risk factors that affect the occurrence and progress of CKD. In recent years, emerging risk factors are being recognized including OSAS [32]. Studies have found that an increasing number of patients with OSAS may suffer from mild CKD [33, 34]. Sklar [35] reported the association between severe OSA and proteinuria. Then, through the treatment of OSAS, proteinuria was relieved. Coincidentally, Daskalopoulou [36] found that compared with healthy people, the albuminuria excretion of OSAS patients increased during sleep. A survey in Japan found that the incidence of CKD in OSAS was much higher than that in people without OSAS $(30.5 \% \text { vs. } 9.1 \%)^{[38]}$. Chou [28] found a significant correlation between the severity of OSAS and renal impairment. Similarly, a large cohort study of US veterans by Molnar [37] found that patients diagnosed with OSAS had a faster decline in renal function.
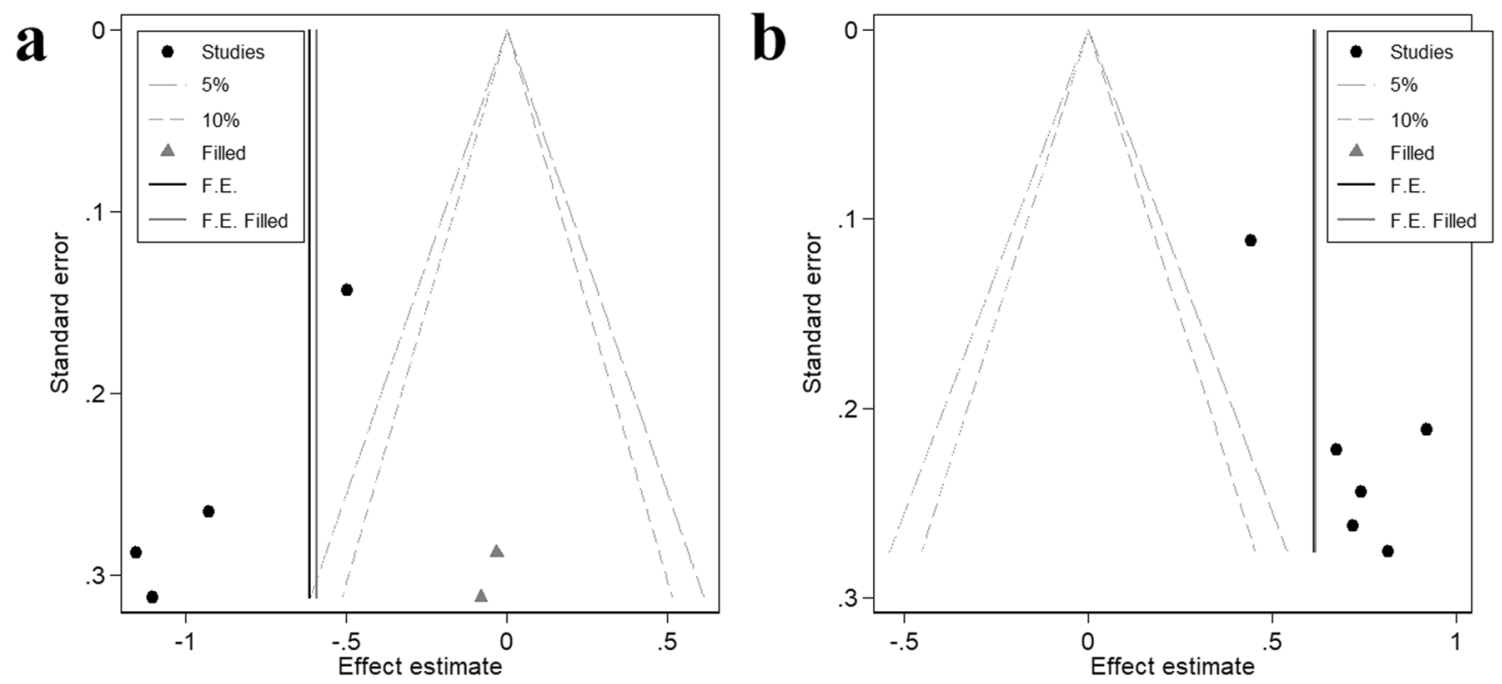

Fig. 5 Additional contour funnel plot. a Cystatin C of severe OSAS vs no OSAS. b Cystatin C of non-diabetes patients with OSAS vs no OSAS 


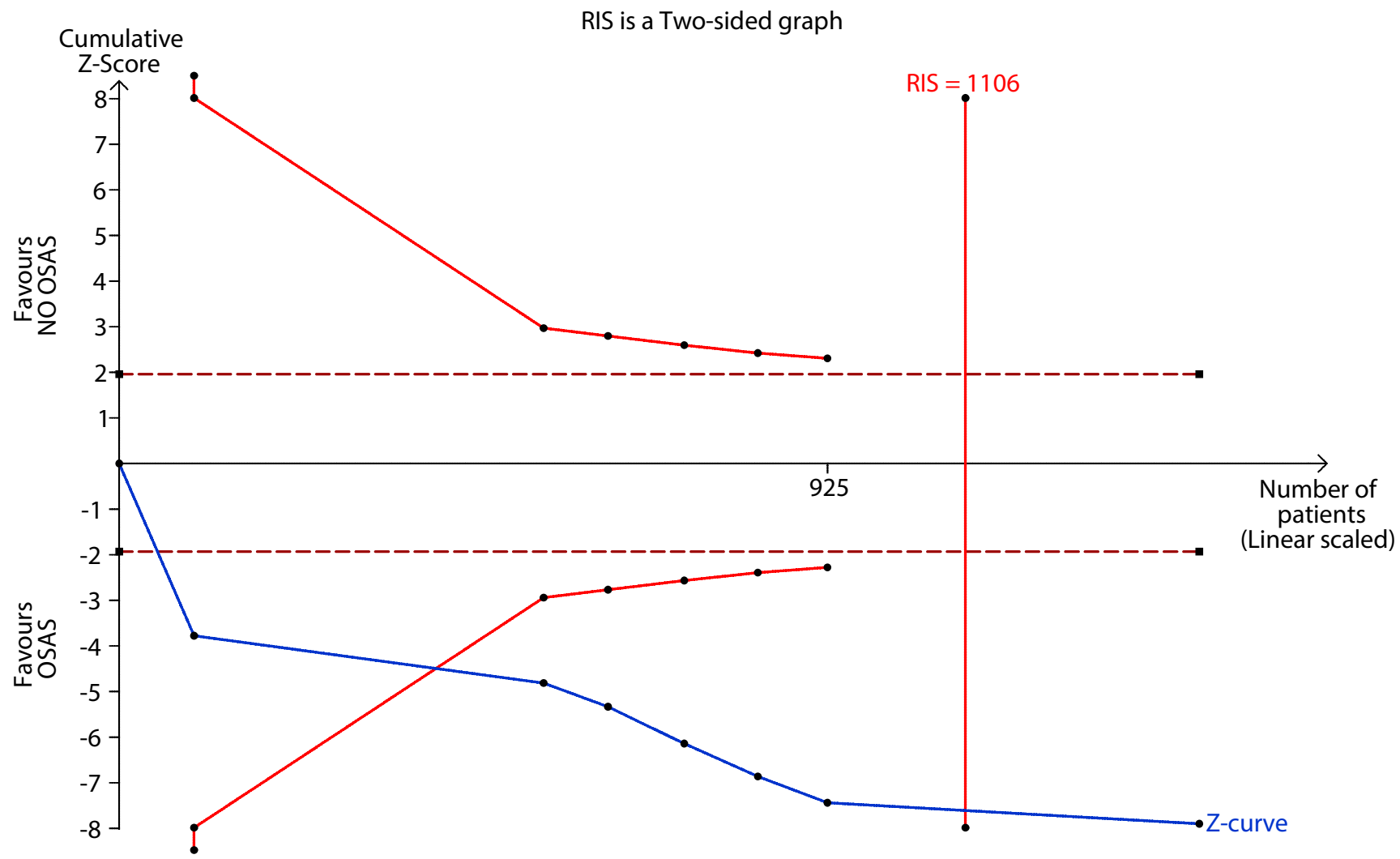

Fig. 6 TSA of the relationship between cystatin C and OSAS

OSAS may result in the occurrence and development of CKD by aggravating traditional risk factors such as hypertension, diabetes, and obesity [38]. On the other hand, hypoxia of renal tissue is considered as an important mediator for the occurrence and progression of CKD [39]. OSAS results in activated hypoxia-inducible factors (HIFs) which causes cascade reactions, such as inflammatory response and endothelial damage [40], ultimately leading to renal damage and dysfunction. Furthermore, hypoxia can induce renal damage by activating sympathetic nervous system or renin-angiotensin-aldosterone system (RAAS), and eventually progresses into CKD [41, 42]. Renal damage caused by OSAS is often manifested as nocturia, microalbuminuria, and renal dysfunction. Consequently, many studies have found that continuous positive airway pressure (CPAP) therapy can effectively alleviate the progress of CKD [43], reverse the decline of eGFR [44], and reduce the urinary albumin excretion (UAE) [45].

Findings from this meta-analysis suggest that the levels of serum cystatin $\mathrm{C}$ and proteinuria in patients with OSAS were significantly higher, and the levels of eGFR were obviously lower than those in healthy people without OSAS. Similarly, compared with mild to moderate OSAS patients, the levels of serum cystatin $\mathrm{C}$, proteinuria, and eGFR in patients with severe OSAS showed the same changes as the above results. Furthermore, our meta-analysis also found an increased risk of CKD in OSAS patients.
Hypertension and diabetes are common risk factors in OSAS and CKD. In order to reduce the potential impact of hypertension and diabetes on this study, we conducted a subgroup analysis of serum cystatin $\mathrm{C}$ and $\mathrm{eGFR}$ based on whether the study included patients with hypertension and diabetes. The results showed that with or without hypertension and diabetes, the levels of cystatin $\mathrm{C}$ increased in OSAS patients, and there was no significant difference between the two groups. Conversely, for eGFR, OSAS with hypertension and diabetes decreased significantly.

Serum cystatin $C$ and urinary microalbumin are considered to be more sensitive markers in the diagnosis of early renal damage. Viazzi [46] reported that $50 \%$ of patients with OSAS may progress to end stage renal disease (ESRD) when they have abnormal urinary microproteins and renal function. Therefore, this metaanalysis shows that OSAS can induce potential kidney damage.

There are some limitations in this study. First, the amount of literature included in this study is small, which may affect the accuracy of our analysis results. Second, some studies have found that obesity and male are more likely to be suffering from OSAS [47], while BMI and gender will affect renal function at the same time. Unfortunately, we cannot exclude the impact of BMI and gender on this study, which may affect the validity of the main results. In addition, the renal damage caused by OSAS is long lasting. However, the studies included in our meta-analysis were cross-sectional, and more cohort studies are needed to confirm our conclusions. 


\section{Conclusion}

This meta-analysis found that OSAS was associated with a higher risk of early renal damage, especially in the patients with hypertension and/or diabetes. The result of TSA verifies the credibility and stability of the conclusions. Patients with OSAS should evaluate renal function regularly aiming to decrease the risk of developing into CKD. Notably, this metaanalysis requires more prospective cohort studies to reduce the impact of confounding factors, so as to clarify whether OSAS is an independent risk factor for renal damage.

Funding information This study was funded by excellent scientific and technological youth program of China Academy of Chinese Medical Sciences Fund (ZZ13-YQ-031).

\section{Compliance with ethical standards}

Conflict of interest The authors declare that they have no conflict of interest.

Ethical approval All procedures performed in studies involving human participants were in accordance with the ethical standards of the institutional and/or national research committee and with the 1964 Helsinki declaration and its later amendments or comparable ethical standards. For this type of study, formal consent is not required.

Open Access This article is licensed under a Creative Commons Attribution 4.0 International License, which permits use, sharing, adaptation, distribution and reproduction in any medium or format, as long as you give appropriate credit to the original author(s) and the source, provide a link to the Creative Commons licence, and indicate if changes were made. The images or other third party material in this article are included in the article's Creative Commons licence, unless indicated otherwise in a credit line to the material. If material is not included in the article's Creative Commons licence and your intended use is not permitted by statutory regulation or exceeds the permitted use, you will need to obtain permission directly from the copyright holder. To view a copy of this licence, visit http://creativecommons.org/licenses/by/4.0/.

\section{References}

1. Basoglu OK, Vardar R, Tasbakan MS, Ucar ZZ, Ayik S, Kose T, Bor S (2015) Obstructive sleep apnea syndrome and gastroesophageal reflux disease: the importance of obesity and gender. Sleep Breath 19(2):585-592. https://doi.org/10.1007/s11325-014-1051-4

2. Strausz S, Havulinna AS, Tuomi T, Bachour A, Groop L, Mäkitie A, Koskinen S, Salomaa V, Palotie A, Ripatti S, Palotie T (2018) Obstructive sleep apnea and the risk for coronary heart disease and type 2 diabetes: a longitudinal population-based study in Finland. BMJ Open 8(1):e022752. https://doi.org/10.1136/bmjopen-2018022752

3. Drager LF, McEvoy RD, Barbe F, Lorenzi-Filho G, Redline S (2017) Sleep apnea and cardiovascular disease: lessons from recent trials and need for team science. Circulation 136(19):1840-1850. https://doi.org/10.1161/CIRCULATIONAHA.117.029400

4. Mello-Fujita L, Kim LJ, Palombini Lde O, Rizzi C, Tufik S, Andersen ML, Coelho FM (2015) Treatment of obstructive sleep apnea syndrome associated with stroke. Sleep Med 16(6):691-696. https://doi.org/10.1016/j.sleep.2014.12.017

5. Li M, Li XY, Lu Y (2018) Obstructive sleep apnea syndrome and metabolic diseases. Endocrinology 159(7):2670-2675.https://doi. org/10.1210/en.2018-00248

6. Voulgaris A, Marrone O, Bonsignore MR, Steiropoulos P (2019) Chronic kidney disease in patients with obstructive sleep apnea. A narrative review. Sleep Med Rev 47:74-89. https://doi.org/10.1016/ j.smrv.2019.07.001

7. Young T, Palta M, Dempsey J, Skatrud J, Weber S, Badr S (1993) The occurrence of sleep-disordered breathing among middle-aged adults. N Engl J Med 328(17):1230-1235. https://doi.org/10.1056/ NEJM199304293281704

8. Abuyassin B, Sharma K, Ayas NT, Laher I (2015) Obstructive sleep apnea and kidney disease: a potential bidirectional relationship? J Clin Sleep Med 11(8):915-924. https://doi.org/10.5664/jcsm.4946

9. Zoccali C, Mallamaci F, Tripepi G (2003) Traditional and emerging cardiovascular risk factors in end-stage renal disease. Kidney Int Suppl 85:S105-S110. https://doi.org/10.1046/j.1523-1755.63.s85. 25.x

10. Krstic D, Tomic N, Radosavljevic B, Avramovic N, Dragutinovic V, Skodric SR, Colovic M (2016) Biochemical markers of renal function. Curr Med Chem 23(19):2018-2040. https://doi.org/10. 2174/0929867323666160115130241

11. Agrawal V, Vanhecke TE, Rai B, Franklin BA, Sangal RB, McCullough PA (2009) Albuminuria and renal function in obese adults evaluated for obstructive sleep apnea. Nephron Clin Pract 113(3):c140-c147. https://doi.org/10.1159/000232594

12. Voulgaris A, Archontogeorgis K, Nena E, Tsigalou C, Xanthoudaki M, Kouratzi M, Tripsianis G, Froudarakis M, Steiropoulos P (2018) Serum levels of NGAL and cystatin C as markers of early kidney dysfunction in patients with obstructive sleep apnea syndrome. Sleep Breath 23(1):1-9. https://doi.org/10.1007/s11325-018-16778

13. Mello P, Franger M, Boujaoude Z, Adaimy M, Gelfand E, Kass J, Weisberg LS (2004) Night and day proteinuria in patients with sleep apnea. Am J Kidney Dis 44(4):636-641

14. Liberati A, Altman DG, Tetzlaff J, Mulrow C, Gøtzsche PC, Ioannidis JP, Clarke M, Devereaux PJ, Kleijnen J, Moher D (2009) The PRISMA statement for reporting systematic reviews and meta-analyses of studies that evaluate healthcare interventions: explanation and elaboration. BMJ 339:b2700. https://doi.org/10. 1136/bmj.b2700

15. Chen Y, Li Y, Jiang Q, Xu X, Zhang X, Simayi Z, Ye H (2015) Analysis of early kidney injury-related factors in patients with hypertension and obstructive sleep apnea hypopnea syndrome (OSAHS). Arch Iran Med `18(12):827-33. 0151812/AIM.007

16. Chen DD, Huang JF, Lin QC, Chen GP, Zhao JM (2019) Relationship between serum adiponectin and bone mineral density in male patients with obstructive sleep apnea syndrome. Sleep Breath 21(2):557-564. https://doi.org/10.1007/s11325-017-1492-7

17. Canales MT, Paudel ML, Taylor BC, Ishani A, Mehra R, Steffes M, Stone KL, Redline S, Ensrud KE (2011) Sleep-disordered breathing and urinary albumin excretion in older men. Sleep Breath 15(1): 137-144. https://doi.org/10.1007/s11325-010-0339-2

18. Zhang XB, Lin QC, Deng CS, Chen GP, Cai ZM, Chen H (2013) Elevated serum cystatin $C$ in severe OSA younger men without complications. Sleep Breath 17(1):235-241. https://doi.org/10. 1007/s11325-012-0678-2

19. Faulx MD, Storferisser A, Kirchner HL, Jenny NS, Tracy RP, Redline S (2007) Obstructive sleep apnea is associated with increased urinary albumin excretion. Sleep 30(7):923-929. https:// doi.org/10.1093/sleep/30.7.923

20. Archontogeorgis K, Nena E, Tsigalou C, Voulgaris A, Xanthoudaki M, Froudarakis M, Steiropoulos P (2016) Cystatin C levels in 
middle-aged patients with obstructive sleep apnea syndrome. Pulm Med 2016:1-8. https://doi.org/10.1155/2016/8081723

21. Ursavas A, Karadag M, Gullulu M, Demirdogen E, Coskun F, Onart S, Gozu RO (2008) Low-grade urinary albumin excretion in normotensive/non-diabetic obstructive sleep apnea patients. Sleep Breath 12(3):217-222. https://doi.org/10.1007/s11325-0080169-7

22. Bulcun E, Ekici M, Ekici A, Cimen DA, Kisa U (2015) Microalbuminuria in obstructive sleep apnea syndrome. Sleep Breath 19(4):1191-1197. https://doi.org/10.1007/s11325-0151136-8

23. Song F, Yi HL (2019) Preliminary study on the relationship between OSA and renal function. J Clin Otorhinolaryngol Head Neck Surg 33(4):298-303. https://doi.org/10.13201/j.issn.10011781.2019.04.004

24. Zeng A (2017) Association between obstructive sleep apnea hypopnea syndrome and urinary microalbumin creatinine ratio in male. Fujian Medical University

25. Yayan J, Rasche K, Vlachou A (2017) Obstructive sleep apnea and chronic kidney disease. Adv Exp Med Biol 1022:11-18. https://doi. org/10.1007/5584 201735

26. Uyar M, Davutoğglu V, Gündoğdu N, Kosovalı Sİ (2015) Renal functions in obstructive sleep apnea patients. Sleep Breath 20(1): 191-195. https://doi.org/10.1007/s11325-015-1204-0

27. Adams RJ, Appleton SL, Vakulin A, Hanly PJ, McDonald SP, Martin SA, Lang CJ, Taylor AW, McEvoy RD, Antic NA, Catcheside PG, Vincent AD, Wittert GA (2017) Chronic kidney disease and sleep apnea association of kidney disease with obstructive sleep apnea in a population study of men. Sleep 40(1). https:// doi.org/10.1093/sleep/zsw015

28. Chou YT, Lee PH, Yang CT, Lin CL, Veasey S, Chuang LP, Lin SW, Lin YS, Chen NH (2011) Obstructive sleep apnea: a standalone risk factor for chronic kidney disease. Nephrol Dial Transplant 26(7):2244-2250. https://doi.org/10.1093/ndt/gfq821

29. Kanbay A, Buyukoglan H, Ozdogan N, Kaya E, Oymak FS, Gulmez I, Demir R, Kokturk O, Covic A (2012) Obstructive sleep apnea syndrome is related to the progression of chronic kidney disease. Int Urol Nephrol 44(2):535-539. https://doi.org/10.1007/ s11255-011-9927-8

30. Hou TT, Zhou C, Xie P, Deng JJ, Xie YP, Li CW, Su P, Zhang WJ, He QL (2016) Clinical investigation for blood levels of cystetine C and superoxide dismutase in patients with obstructive sleep apnea syndrome related hypertension. Chinese Circulation Journal 31(5): 463-466

31. Jha V, Garcia-Garcia G, Iseki K, Li Z, Naicker S, Plattner B, Saran R, Wang AY, Yang CW (2013) Chronic kidney disease: global dimension and perspectives. Lancet 382(9888):260-272. https:// doi.org/10.1016/S0140-6736(13)60687-X

32. Ku E, Johansen KL, Mcculloch C (2018) Time-centered approach to understanding risk factors for the progression of CKD. Clin J Am Soc Nephrol 13(5):693-701. https://doi.org/10.2215/CJN. 10360917

33. Sakaguchi Y, Hatta T, Hayashi T, Shoji T, Suzuki A, Tomida K, Okada N, Rakugi H, Isaka Y, Tsubakihara Y (2013) Association of nocturnal hypoxemia with progression of CKD. Clin J Am Soc Nephrol 8(9):1502-1507. https://doi.org/10.2215/CJN.11931112

34. Nicholl DDM, Ahmed SB, Loewen AHS, Hemmelgarn BR, Sola DY, Beecroft JM, Turin TC, Hanly PJ (2012) Declining kidney function increases the prevalence of sleep apnea and nocturnal hypoxia. Chest 141(6):1422-1430. https://doi.org/ 10.1378/chest.11-1809

35. Sklar AH, Chaudhary BA (1988) Reversible proteinuria in obstructive sleep apnea syndrome. Arch Intern Med 148:87-89

36. Daskalopoulou EG, Liavvas C, Nakas CT, Vlachogiannis EG, Bouros D, Dombros NV (2011) Obstructive sleep apnoea syndrome promotes reversal albuminuria during sleep. Sleep Breath 15(3):589-597. https://doi.org/10.1007/s11325-010-0408-6

37. Molnar MZ, Mucsi I, Novak M, Szabo Z, Freire AX, Huch KM, Arah OA, Ma JZ, Lu JL, Sim JJ, Streja E, Kalantar-Zadeh K, Kovesdy CP (2015) Association of incident obstructive sleep apnoea with outcomes in a large cohort of US veterans. Thorax 70(9): 888-895. https://doi.org/10.1136/thoraxjnl-2015-206970

38. Mirrakhimov AE (2012) Obstructive sleep apnea and kidney disease: is there any direct link? Sleep Breath 16(4):1009-1016. https://doi.org/10.1007/s11325-011-0624-8

39. Ow CPC, Ngo JP, Ullah MM, Hilliard LM, Evans RG (2017) Renal hypoxia in kidney disease: cause or consequence? Acta Physiol 222(4):e12999. https://doi.org/10.1111/apha.12999

40. Dempsey JA, Veasey SC, Morgan BJ, O’Donnell CP (2010) Pathophysiology of sleep apnea. Physiol Rev 90(1):47-112. https://doi.org/10.1152/physrev.00043.2008

41. Ahmed SB, Ronksley PE, Hemmelgarn BR, Tsai WH, Manns BJ, Tonelli M, Klarenbach SW, Chin R, Clement FM, Hanly PJ (2011) Nocturnal hypoxia and loss of kidney function. PLoS One 6(4): e19029. https://doi.org/10.1371/journal.pone.0019029

42. Sakaguchi Y, Hatta T, Hayashi T, Shoji T, Suzuki A, Tomida K, Okada N, Rakugi H, Isaka Y, Tsubakihara Y (2013) Association of nocturnal hypoxemia with progression of CKD. JASN 8(9):15021507. https://doi.org/10.2215/CJN.11931112

43. Kinebuchi SI, Kazama J, Satoh M, Sakai K, Nakayama H, Yoshizawa H, Narita I, Suzuki E, Gejyo F (2004) Short-term use of continuous positive airway pressure ameliorates glomerular hyperfiltration in patients with obstructive sleep apnoea syndrome. Clin Sci 107(3):317-322. https://doi.org/10.1042/CS20040074

44. Nicholl DD, Hanly PJ, Poulin MJ, Handley GB, Hemmelgarn BR, Sola DY, Ahmed SB (2014) Evaluation of continuous positive airway pressure therapy on renin-angiotensin system activity in obstructive sleep apnea. Am J Respir Crit Care Med 190(5):572-580. https://doi.org/10.1164/rccm.201403-0526OC

45. Zehra AY, Ucar ZZ, Demir AU, Kirakli C, Kalenci D, Tibet G (2014) Does CPAP therapy alter urinary albumin level in adult patients with moderate to severe obstructive sleep apnea syndrome? Sleep Breath 18(3):525-532. https://doi.org/10.1007/s11325-0130914-4

46. Viazzi F, Leoncini G, Conti N, Tomolillo C, Giachero G, Vercelli M, Deferrari G, Pontremoli R (2010) Microalbuminuria is a predictor of chronic renal insufficiency in patients without diabetes and with hypertension: the MAGIC study. Clin J Am Soc Nephrol 5(6): 1099-1106. https://doi.org/10.2215/CJN.07271009

47. Xanthopoulos MS, Berkowitz RI, Tapia IE (2018) Effects of obesity therapies on sleep disorders. Metabolism 84:109-117. https:// doi.org/10.1016/j.metabol.2018.01.022

Publisher's note Springer Nature remains neutral with regard to jurisdictional claims in published maps and institutional affiliations. 